\title{
\#MinhaExperiênciaNoSUS: um estudo dos sentidos sobre o SUS com-partilhados no Facebook
}

\author{
Clarisse Castro Cavalcantel \\ https://orcid.org/0000-0002-3883-2166 \\ Daniela Muzi \\ https://orcid.org/0000-0002-0706-5961 \\ I -Fundação Oswaldo Cruz \\ Rio de Janeiro (RJ), Brasil
}

Resumo: O presente artigo apresenta uma análise dos discursos das narrativas de participantes da campanha \#MinhaExperiênciaNoSUS. A campanha foi produzida pelo site PenseSUS, que disponibiliza diferentes conteúdos sobre o Sistema Único de Saúde (SUS) para promover o debate e a reflexão acerca da política nacional de saúde no Brasil, e circulou em sua fanpage no Facebook. Com o aporte teórico de autores como Foucault, Pêcheux, Goffman e Charaudeau, descrevemos os sentidos produzidos a partir das experiências dos usuários e suas possíveis significações em termos de produção de memória sobre o SUS. Quais sejam: um Sistema que marca pelo acolhimento, pela presença do médico, pela estrutura física da oferta e por procedimentos tradicionais como a imunização.

Palavras-chave: discursos; narrativas; Facebook; Sistema Único de Saúde.

Abstract: \#MyExperiencelnSUS: a study of the senses about SUS shared in Facebook - The present article presents an analysis of the discourses about the narratives of participants in the campaign \#MyExperiencelnSUS. The campaign was produced by the PenseSUS website, which provides different contents about the Unified Health System (SUS) to promote debate and reflection on the national health policy in Brazil, and circulated in its fan page on Facebook. With the theoretical contribution of authors like Foucault, Pêcheux, Goffman and Charaudeau, we describe the senses produced from the experiences of the users and their possible meanings in terms of memory production on SUS. Which are: a system that marks the reception, the presence of the doctor, the physical structure of the offer and traditional procedures such as immunization.

Keywords: discourses; narratives; Facebook; Unified Health System. 


\section{Introdução}

A participação social permanece como um dos grandes desafios para o fortalecimento do Sistema Único de Saúde (SUS). Sendo uma das diretrizes do Sistema, caracteriza-se como o movimento por meio do qual a população, "de forma democrática, participa dos processos decisórios, por meio da fiscalização e desenvolvimento das políticas de saúde" (NUNES et al, 2009, p.2). A Lei 8.142/90 define espaços institucionalizados por meio dos quais poderá ser exercida essa participação, que são os Conselhos e Conferências de Saúde. Ao mesmo tempo, a transformação desse ideário em práticas sociais ativas e permanentes depende significativamente do contexto político em questão. Dada a atual conjuntura, em que perdas de direitos sociais se concretizam paulatinamente, é preciso encontrar frestas que possibilitem outros mecanismos de participação, menos institucionalizados e de mais fácil execução. Antes de tudo, é preciso considerar que a relação da participação social com a comunicação é ontológica: "[...] sem comunicação universal, equitativa, integral, descentralizada e hierarquizada, dificilmente teremos uma participação como a desejada e vice-versa" (ARAúJO; CARDOSO, 2007, p.83). Por isso mesmo se faz necessário " [...] desenvolver espaços, processos e práticas que ampliem as vozes mais periféricas, sejam das comunidades discursivas, dos trabalhadores da saúde ou da população [...], permitindo-Ihes disseminar seus interesses e pontos de vista" (Idem, p.84).

Neste sentido, as novas tecnologias de informação e comunicação (TICs) têm se mostrado de grande relevância e potencialidade, quando se assume que o uso social da internet favoreceu a interação entre sujeitos (indivíduos e também instituições) e a disseminação de práticas materiais e simbólicas de participação. São inúmeras possibilidades de expressão que a internet põe em circulação e contato, produzidas por pessoas com os mais diversos níveis de capital cultural e financeiro, inseridos de forma mais ou menos confortável na "cultura contemporânea marcada pelas tecnologias digitais" (LEMOS, 2003, p.11), enquanto modo de ser sujeito no mundo.

As experiências de uso das redes sociais em ambientes virtuais são algumas das principais materializações das TICs. Além de se configurarem como espaços de interlocução mediados pelas novas tecnologias, segundo Kirkwood (2006), essas experiências se constituem cada vez mais como movimentos de formulação de identidade e pertencimento, e como ponto de partida ou de convergência no contato com diferentes tipos de navegação, apropriações e construções de conhecimentos nas mais diversas áreas.

Tais experiências podem ser relacionadas ao conceito de mobilização social, que está na miríade dos processos comunicacionais que se pretendem mais horizontais e menos ortodoxos, e que envolvem a participação social enquanto objetivo. Ou seja, uma mobilização motivada por princípios de autonomia, "no sentido de constituir sujeitos capazes de interferir no mundo e construir a própria realidade" (MAFRA, 2010, p.107). Portanto, para materializar práticas de mobilização, os sujeitos recorrem aos atos de interações e trocas, utilizando meios, linguagens e instrumentos com os quais convivem em sociedade. 
Castells e Cardoso (2005) explicam que as experiências em rede se ampliaram, historicamente, da esfera privada para a esfera pública. Além disso, para eles, as tecnologias virtuais são capazes de organizar e distribuir a informação e o conhecimento de modo autônomo, podendo ser flexíveis e adaptáveis graças à sua capacidade de descentralização. No entanto, é preciso relativizar o potencial democrático da internet, uma vez que, mediada pelos algoritmos e com muitos espaços proprietários, não se trata de um espaço neutro e, da mesma forma, práticas de comunicação lineares e unidirecionais podem ser reproduzidas de novas maneiras nos meios digitais.

Neste contexto, o Brasil se configura atualmente como um dos maiores usuários de redes sociais virtuais no mundo, o maior na América Latina, com cerca de 78 milhões de perfis presentes apenas no Facebook e Twitter em 2014 (BRASIL É..., 2016). São pessoas, empresas e instituições que se avolumam progressivamente nesses ambientes, buscando interação, visibilidade e reconhecimento. O site PenseSUS ${ }^{1}$ - a reflexão fortalece essa conquista (www.pensesus.fiocruz.br) é um desses sujeitos, tendo, em 2016, criado perfis nessas redes sociais com o intuito de ampliar as práticas comunicativas, buscando uma comunicação mais equânime que servisse como espaço para a escuta e circulação ${ }^{2}$ e sentidos sociais sobre o SUS.

Dentre as estratégias de comunicação criadas para as redes, destaca-se a campanha \#MinhaExperiênciaNoSUS, que visava a promover o engajamento e participação dos usuários da internet a partir do uso dessa hashtag3. A campanha desenvolvida para o Facebook consistiu-se numa mobilização para o compartilhamento público de depoimentos que narrassem experiências no SUS - não apenas o uso específico dos estabelecimentos de saúde, mas de contato ampliado com as políticas de prevenção e promoção da saúde. Os depoimentos, em texto ou vídeo, eram publicados pelos usuários em suas timelines (linha do tempo) ou recebidos por e-mail e postados publicamente no perfil do PenseSUS no Facebook, espaço em que era possível receber reações ${ }^{4}$, comentários de outros usuários

1 Criado em 2014, em comemoração aos 25 anos do SUS, é uma iniciativa da Fundação Oswaldo Cruz (Fiocruz), desenvolvida pelo Instituto de Comunicação e Informação Científica e Tecnológica em Saúde (Icict/Fiocruz) em parceria com o Centro Brasileiro de Estudos de Saúde (Cebes) e a Associação Brasileira de Saúde Coletiva (Abrasco). Por meio do fomento do Programa de Indução à Pesquisa \& Desenvolvimento Tecnológico (PIPDT/ Icict/Fiocruz), em 2016, foi possível ampliar a equipe do site e desenvolver a experiência de criação e moderação de perfis no Facebook e Twitter.

2 O conceito de circulação, como propõem José Luiz Braga e Antonio Fausto Neto, pressupõe uma concepção mais ampla que a relação entre emissão e recepção, um lugar posterior que ultrapassa e reformula o próprio conceito de recepção, transformando os processos de interação. A circulação manifesta-se como local de observação de valores simbólicos e da produção e recepção de sentidos. Cf. BRAGA, J. L. Circuitos versus campos sociais. In: Mediação \& Mediatização. Salvador; Brasília: EDUFBA; Compós, 2012a. p. 31-52 e FAUSTO NETO, A. As bordas da circulação. Alceu, v. 10, n. 20, p. 55-69, 2010.

3 Forma de indexação de assuntos na internet composta pelo sinal gráfico cerquilha "\#" associado a palavraschave. Na internet transformam-se em hiperlinks indexáveis, permitindo a busca e descoberta por mecanismos como o Google.

4 Opções de reação além do "curtir". São elas: "Amei"; "Haha"; "Uau";"Triste" e "Grr". Essa alteração realizada em 2016 pelo Facebook responde a uma demanda recorrente dos usuários da rede social por conta da inadequação e limitação do botão curtir para expressar, por exemplo, reações perante notícias tristes, como um falecimento, ou que causavam sentimento de revolta, como um ato de violência. 
ou ainda compartilhamentos em outros perfis, movimentando a rede de produção de sentidos, a circulação da campanha em si e a interação dos participantes.

Com isso, pretendia-se promover maior circularidade de experiências com caráter diversificado. Para Charaudeau (2006, p. 118), o discurso circulante é a marca de um tempo, temas recorrentes que são propalados dentro do campo social, a "soma empírica de enunciados com visada definicional sobre o que são os seres, as ações, os acontecimentos, suas características, seus comportamentos e os julgamentos a eles ligados". Na convocatória da campanha, feita pelas redes sociais e em outros dispositivos midiáticos, foi solicitado que as pessoas enviassem suas histórias em formato de texto ou vídeo, para publicação no Facebook. Elas poderiam também publicar suas vivências em seus próprios perfis, usando a hashtag da campanha como marcador de identificação.

Mas do que tratam esses depoimentos? Como os sujeitos que se mobilizaram pela campanha estão vivenciando experiências no SUS? Quais são essas vivências e como elas se materializam em discursos circulantes? Dessa maneira, o objetivo deste artigo é mapear os discursos presentes nessas narrativas e, a partir disso, compreender os sentidos de SUS que são postos em circulação através da internet. Para isso, recorremos fundamentalmente ao aporte teórico da análise de discursos francesa, convocando autores como Patrick Charaudeau e Michel Pêcheux; e sua vertente brasileira a partir da Semiologia dos Discursos Sociais, com Inesita Araújo; colocando-os em diálogo com referências dos campos da sociologia e antropologia como Michel Foucault, Erving Goffman e Leonor Arfuch. Todos têm na linguagem e suas implicações sociais e políticas o aspecto central de suas abordagens. Ainda que sejam autores que antecedem a invenção e os usos da internet, suas contribuições para os estudos discursivos e interacionais não só não se esgotam quanto se dotam de novas potências e significados neste século. A análise da dimensão discursiva dos depoimentos e comentários ajuda-nos a compreender as práticas e sentidos sociais instaurados no compartilhamento de informações na internet, uma vez que circulam e deixam rastros na rede. Acredita-se que esse exercício analítico possa ajudar a entender melhor a potência da comunicação em rede, da circularidade característica da internet, e da escuta diversificada dos usuários do Sistema. E é também esforço de apreender e atualizar dinâmicas de fala e escuta, que podem também ser ressignificadas como dinâmicas de participação social no SUS, a partir dos usos das TICs.

\section{Metodologia}

Como etapa inicial da pesquisa, foi realizada a sistematização dos depoimentos produzidos pelos participantes da campanha \#MinhaExperiênciaNoSUS. A primeira experiência foi publicada no dia 14 de fevereiro e a última no dia 19 de maio de 2017. Foram mapeados 25 depoimentos, entre textos e vídeos, cujos conteúdos permanecem disponíveis para leitura e interação na fanpage do PenseSUS no Facebook (facebook.com/pensesusoficial). 
Para este artigo, foram considerados, para análise, os 20 depoimentos encaminhados em formato textual. Foram realizadas diversas leituras para a identificação de pontos-chave sobre os sujeitos, os contextos, os modos de dizer e os conteúdos das falas. Esses pontos-chave deram origem a categorias de análise, nas quais os depoimentos puderam ser agrupados.

Em se tratando de narrativas como discursos postos em circulação através de uma rede social, para compreender as modulações presentes nesses discursos, foi preciso identificar suas regularidades. O que há de comum nessas narrativas? É sobre tais regularidades que se apoia a memória discursiva, que fundamenta toda prática discursiva, e de onde partem os novos ou velhos efeitos de sentido sobre algo. A "memória deve ser entendida aqui não no sentido diretamente psicologista da 'memória individual', mas nos sentidos entrecruzados da memória mítica, da memória social inscrita em práticas, e da memória construída do historiador" (PÊCHEUX, 2008, p.50).

O significado do discurso se apoia na memória discursiva que, por sua vez, opera a partir da repetição de enunciados que formam regularidades discursivas. Tais regularidades nos apontam, ainda, as formações discursivas predominantes nas narrativas, "aquilo que, numa conjuntura dada, determinada pelo estado de luta de classes, determina o que pode e deve ser dito" (PÊCHEUX, 1995, p.160). Tais discursos são produzidos socialmente, e por isso se torna importante tratá-los "como práticas que formam sistematicamente os objetos de que falam" (FOUCAULT, 2015, p.60).

Dentre as práticas que mais significativamente promovem representações e memórias sobre o SUS estão as coberturas noticiosas promovidas pelos meios de comunicação de massa, que mantêm cotidianamente as políticas de saúde como temas de interesse público, garantindo-lhes visibilidade, ainda que tal interesse seja marcado frequentemente pela apresentação de um Sistema sucateado, com pouca mão de obra disponível, e que, exceto por um ou outro procedimento mais complexo realizado, só gera uma sensação de abandono e desrespeito junto aos contribuintes brasileiros. Isto pode ser visto tanto a partir de uma leitura corriqueira dos jornais, com seus perfis voltados à valorização do factual e ao exercício da denúncia; quanto em trabalhos acadêmicos que destacam a negativação do SUS pela mídia como uma de suas principais estratégias de construção da realidade sobre a saúde pública brasileira. São exemplos disso: Silva (2010), que ao analisar a Folha de São Paulo depara-se com uma extensa produção de sentidos de ineficácia do SUS e incompetência do governo; e Cavalcante (2014), que observa a produção de sentidos de precariedade atribuídos ao SUS pela mídia a partir de críticas permanentes ao Sistema.

Os textos publicados no Facebook, durante a campanha, ficaram disponíveis para receber as reações e os comentários dos usuários da rede, a partir dos quais foi possível verificar a circulação dos discursos e também alguns movimentos de interação entre os presentes. Antes restrito ao intervalo entre os dois polos, o conceito de circulação, agora entendido como um lugar posterior à recepção, é visto com maior complexidade, sendo também importante lugar de observação dos processos de produção de sentidos. 
Dessa maneira, as reações e comentários, ao permanecerem expostos aos visitantes da página, estimularam a produção de outras reações e comentários, gerando novas camadas de interlocução.

\section{Resultados e Discussão}

Antes da apresentação dos discursos mapeados, convém destacar que uma campanha do tipo \#MinhaExperiênciaNoSUS carrega, em seu bojo, uma subjetividade comum às narrativas de vida, ou fragmentos dessas narrativas presentes nas redes sociais on-line, espaço biográfico da atualidade, remetendo à perspectiva de Leonor Arfuch (2010). Subjetividade que está na ordem da linguagem, seja ela textual ou audiovisual, e que ocupa cotidianamente tais esferas coletivas. Gregolin defende que "a subjetividade não se situa no campo individual, mas no de todos os processos de produção social e material e, consequentemente, o sujeito moderno é um consumidor de subjetividade: ele consome sistemas de representação, de sensibilidades" (GREGOLIN, 2007, p.21).

Segundo Arfuch (2010), o espaço biográfico na atualidade é local em que convivem formas tradicionais de discurso biográfico, como as biografias e autobiografias, e as formas contemporâneas de relato, como blogs e redes sociais. Enquanto "os gêneros canônicos são obrigados a respeitar certa verossimilhança da história contada [...] outras variantes do espaço biográfico podem produzir efeito altamente desestabilizador, talvez como 'desforra' diante de um excesso de referencialidade 'testemunhal'" (ARFUCH, 2010, p.127).

Nesses espaços, as pessoas são interlocutoras de suas próprias vivências, que têm como principal matéria-prima o seu próprio olhar sobre os acontecimentos. Neste sentido, não há a necessária presença de um olhar especializado sobre um tema, elemento tão caro a alguns dispositivos comunicacionais como o próprio jornalismo; tampouco a conformação de uma estrutura linear de informação que recorra a uma objetividade ou a uma padronização da fala. Ao contar as próprias experiências, os sujeitos já deliberam sem muitas delongas sobre aquilo que consideram essencial: o sentimento sobre a vivência narrada, que, positiva ou negativa, imprimiu valores à relação SUS x usuário; e desse "sentir" expresso é composto o material de análise.

Outro aspecto a ser destacado é que a campanha \#MinhaExperiênciaNoSUS foi uma proposta de exposição de temas que são, em essência, de delicada abordagem. São pessoas que, no geral, narraram episódios de sofrimento e até de superação, em decorrência também dos modos pelos quais tiveram acesso às ações e serviços de saúde. Na miríade de campanhas contemporâneas com uso de hashtags, essa tinha o intuito de acionar diferentes dimensões do tema saúde no cotidiano dos usuários da rede social Facebook. A dimensão do direito à saúde, do direito à comunicação e expressão e do próprio direito à reflexão sobre o cuidado e sobre as formações discursivas que imperam hegemonicamente neste terreno - os discursos sobre acesso, espera, tratamento, denúncia. 
É preciso considerar que, ao publicarem seus depoimentos, os participantes estavam cientes de que estariam em contato com uma não restrição de audiência, podendo vir qualquer retorno e de qualquer espécie, pois uma publicação em rede social é uma provocação, que pode ou não ser acolhida por quem a recebe. E por isso mesmo é possível considerar que os usuários de redes sociais estão permanentemente gerenciando impressões, sobre si e sobre o outro, a partir do jogo de discursividades vivenciado nessas plataformas. "Na tentativa de encenar o self personagem com sucesso, é necessário um autocontrole dramatúrgico para imprimir a expressão certa durante o ato e mostrar apenas a parte mais interessante de si" (OLIVEIRA, 2017, p.114).

Os depoimentos publicados no Facebook remetem à noção de face expressa por Goffman: "A face é uma imagem do self delineada em termos de atributos sociais aprovados" (GOFFMAN, 1967, p.5). Segundo Recuero (2014), interagir apresenta riscos à face. Uma face positiva é formada a partir de interações que legitimam a face apresentada, gerando capital social para a relação entre os atores. Um exemplo disso seriam as reações positivas e comentários de apoio. Já a face negativa é formada por falas ofensivas, em desaprovação ou descrédito, o que corresponderia aos comentários e reações negativos.

Feitos os destaques, apresentamos o público participante da campanha. Dos 20 depoimentos ${ }^{5}$ analisados, apenas quatro foram encaminhados por homens. Um número que já era esperado, uma vez que 76\% dos 881 seguidores do PenseSUS no Facebook são mulheres, de acordo com dados analisados em 20 de janeiro de 2018. Uma correspondência que ocorre também com a origem geográfica das narrativas enviadas, 90\% do Rio de Janeiro, cidade que comporta a maior parte dos seguidores da página (263).

O primeiro ponto em comum nas narrativas é que elas relatam o acolhimento recebido pelos depoentes nos serviços do SUS. Caracterizações tais como 'bom', 'ruim', 'confortável', 'desconfortável', 'segura' são declaradas a respeito das práticas de atendimento, adjetivando os modos como se desenvolve o contato profissional de saúdeusuário do sistema, e produzindo sentidos para as experiências de uso dos serviços. Tais caracterizações, oriundas de pacientes ou acompanhantes (vez ou outra também de profissionais de saúde), são os elementos que primeiro fornecem substância às narrativas e apresentam o sujeito SUS emergindo a partir dessas perspectivas relacionais. São os modos como os sujeitos são atendidos, ouvidos, orientados, que falam sobre o atendente em si, o próprio SUS, procurado diante de uma necessidade de saúde, como nos depoimentos 2, 5 e 11, que trazem aspectos da percepção dos usuários sobre o modo como foram acolhidos.

[2] Nos primeiros minutos ela [a médica que atendeu] foi muito acolhedora e me mostrou, no mural do consultório, o mosaico de fotos de crianças e mães com HIV". Até a ocorrência de uma mudança de tom no acolhimento, quando a médica "começou a me fazer perguntas, muitas delas com ar de repreensão.

5 A coleta dos depoimentos foi orientada a partir dos procedimentos exigidos pelo Comitê de Ética, que recomenda o anonimato dos sujeitos de pesquisa envolvidos. Dessa forma, os depoentes não foram identificados, optando-se pelo uso de numeração. 
[5] Em agosto de 2009 eu conhecio SUS, eu vi um médico atencioso, preocupado com o nosso bem-estar, preocupado em nos esclarecer todas as dúvidas a respeito dos prognósticos de uma criança com diabetes tipo 1.

[11] Ainda bem que no posto encontrei Iracema, uma enfermeira querida, que olhou nos meus olhos, nos encaminhou a uma sala de acolhimento [...] Naquele dia, Iracema me disse para segurar firme o braço dele e que não havia motivo para sofrimento.

Esse contato inicial, essa porta de entrada conformada pelo acolhimento, é um aspecto presente em todas as narrativas, sejam elas positivas ou negativas, pano de fundo que fornece substância a todos os discursos. E que acontecem porque há interação entre as pessoas como elemento central das experiências. A afetividade é a marca que modula as experiências, contribuindo para sua apreensão pela memória.

O segundo ponto de destaque da análise é que o acolhimento que emerge das narrativas tem como principal representante o médico que atua no serviço. Ele é um elemento central dentre o que os depoentes buscam destacar em suas experiências. Quando o atendimento é positivo, geralmente, é pelo modo como o paciente foi positivamente atendido pelo médico, assim como é válido o oposto. Os depoimentos 8, 10 e 12 expressam essa personificação.

[8] Sem falar dos médicos, algum deles bons, porém outros suficientemente capazes de dizer coisas do tipo 'agora é pedir a Deus que ela melhore'.

[10] O médico depois apareceu (como por encanto) só pra assinar a receita do remédio. O médico entrou na sala, falando com o enfermeiro sobre mim, perguntou o que me indicou de remédio.

[12] Fui super bem atendida por uma médica que não era oftalmologista, mas avaliou meus olhos e passou um colírio que resolveu o problema sem estragar o fim das férias.

As narrativas também apontam muitos elementos sobre a estrutura física dos serviços de saúde, outra camada de relevância das práticas expressas nos depoimentos. Seja porque falta algo considerado necessário ou porque algo de bom está presente no ambiente, a estrutura é também personagem das vivências.

[1] Mais uma vez fui com meu pai na UPA e fiquei reparando na estrutura. [...] Cara, que hospital privado tem essa estrutura assim horizontal tudo do lado do outro? Esse projeto é fantástico.

[14] Duas horas depois disso fui chamada ao consultório médico, onde me revelaram não realizar aquele tipo de atendimento por não possuírem o apare/ho que examinava ouvido. 
[15] Todas as vezes que fui com minha vó na UPA de Botafogo eu tive essa impressão. Sempre com o olhar de espanto pela estrutura, pelo atendimento.

São efeitos de sentidos variados, que se produzem a partir da escolha de certas palavras para materializar a noção de eficácia (fantástico), de surpresa (olhar de espanto) e também de precariedade (carente de muitas coisas). E há em cada um dos ditos um resvalar de expectativas que falam sobre outras coisas para além da estrutura, dialogando com a noção de direito de ser bem atendido por um sistema que funciona, com o susto pelo bom funcionamento, quando, talvez, a expectativa fosse negativa ou diferente, e com a memória de estabelecimentos já conhecidos pela baixa qualidade de sua estrutura etc.

Aqui também é válido avaliar os contextos sociais que organizam as experiências. Os dois elogios sobre a estrutura da Unidade de Pronto Atendimento (UPA) tratam do mesmo estabelecimento, situado na Zona Sul do município do Rio de Janeiro, no bairro de Botafogo, parte da região onde sabidamente as estruturas públicas funcionam melhor, posto que disponíveis a públicos de maior poder aquisitivo, além de serem estruturas construídas para o atendimento de menor número de pessoas, diferentemente dos hospitais aos quais se referem os depoimentos 8 e 14.

Além das impressões sobre o acolhimento, da presença do médico como elemento central e da percepção sobre a estrutura ofertada, a noção de que "A saúde é direito de todos e dever do Estado", como preconiza o Artigo 196 da Constituição Federal de 1988, também está presente nas narrativas, dando o tom da necessidade de melhora do SUS.

[3] Sou grata por minha filha ter suas vacinas nos postos de saúde, mas acho que isso não é mais que obrigação do governo.

[5] Fazendo buscas na internet descobri informações sobre os direitos do portador de diabetes no Brasil e sobre o cadastro nacional de pacientes do SUS. [...] Confesso que não tinha perspectivas positivas, mas precisava conhecer todas as possibilidades, já que fazer parte do cadastro nacional de pessoas com diabetes do SUS garantiria direitos ao meu filho.

[16] Passei um e-mail para o IFF relatando o acontecido e obtive retorno por parte deles. Estou agendada para a data 10/03/2017, consulta e exame. Gente, muita coisa acontece no SUS, basta lutarmos para fazer valer nossos direitos.

Como a campanha \#MinhaExperiênciaNoSUS apelou para a busca de narrativas em quaisquer periodicidades, foi interessante identificar uma memória discursiva sobre o SUS regular em vários depoimentos: a memória sobre a vacinação. Ela esteve presente nos depoimentos 9, 13 e 18.

[9] Eu tinha quase 3 aninhos e estava participando da vacinação com o Zé Gotinha. Aquele tanto de criança reunida no centro da cidade, e um homem fantasiado de Zé Gotinha pra nos divertir, marcaram minha memória. 
[13] \#MinhaExperiênciaNoSUS foi nos meus primeiros dias de vida, quando fui vacinado para uma série de doenças que somente um sistema público de saúde consegue prevenir e erradicar.

[18] Na verdade, foi uma boa surpresa, porque cheguei lá para ser vacinada ao final da tarde, e fui muito bem atendida e informada em todos os aspectos, sem filas e sem burocracia.

As práticas de vacinação foram o serviço mais mencionado (25\% dos depoimentos citavam a vacinação) e também o mais elogiado pelas pessoas que encaminharam depoimentos para a campanha, o que de certa forma depõe sobre a identidade consolidada dessa oferta no SUS. Uma memória que segue sendo ressignificada a cada período histórico e a cada contexto, constituindo aspecto significativo da rede de sentidos sobre o SUS. A imunização parece ser, assim, um dos elementos de mais forte associação às políticas públicas de saúde, seja quando mencionada por sua periodicidade de oferta ou pela noção da oferta como um direito.

Parte dos depoimentos que circularam na campanha, e aqui analisada, foi produzida na forma de comentários: usuários comentaram postagens de outros participantes da campanha e postagens de instituições parceiras na divulgação da campanha, gerando depoimentos a partir da inserção da hashtag \#MinhaExperiênciaNoSUS. Comentários que apenas configurassem opiniões a respeito das narrativas não foram identificados. As práticas discursivas figuraram mais ao modo de oferta de informações e referências, pois algumas experiências nomearam os estabelecimentos do SUS e acabaram por divulgar alguns serviços sob a ótica da experiência de uso. Foram os próprios usuários do Sistema falando de seus itinerários terapêuticos e assim comunicando sobre trajetórias possíveis nas redes de atendimento.

\section{Considerações finais}

O artigo teve como objetivo mapear os discursos presentes nas narrativas da campanha \#MinhaExperiênciaNoSUS e, a partir disso, compreender os sentidos de SUS postos em circulação através da internet. Usou-se como metodologia a reunião dos discursos e sua divisão em blocos a partir de seus elementos mais regulares, aqueles presentes em três ou mais depoimentos, obtendo-se uma memória discursiva e circulante sobre o SUS a partir das narrativas autobiográficas.

Como vimos na seção anterior, foram basicamente cinco as regularidades que emergiram dos discursos: o acolhimento como um espaço de interlocução e de significação da experiência; o médico como personagem central do atendimento e como baliza de sua qualidade; as impressões sobre a estrutura como elementos que agregaram valor positivo ou negativo às experiências; a perspectiva do acesso aos serviços como um direito civil; 
e as práticas de imunização como as mais solidificadas no imaginário social dos serviços ofertados pelo SUS.

Algumas assertivas depreendem-se dessa análise. A primeira é o entendimento, por parte dos participantes da campanha, de que falar sobre suas experiências no SUS era essencialmente falar sobre o modo como foram tratados durante o contato com os serviços. O acolhimento é um elemento central, por ser aspecto que se dá na ordem do universo individual, íntimo, sobre o qual os pacientes ou acompanhantes sentiram-se autorizados à expressão. Também é aspecto fundamental porque abrange a dimensão consumidor/cidadão, numa perspectiva em que o profissional de saúde é um prestador de serviço, que como tal precisa atender a determinadas expectativas. E é relevante porque adensa e organiza as emoções presentes na materialidade da experiência. Falar sobre o acolhimento possibilita ao narrador trazer à esfera pública as expressões sobre si e sobre o outro, constituindo a encenação de self característica das narrativas autobiográficas.

Em seguida, foi interessante perceber a centralidade ocupada pela figura do médico como provedor de cuidado, reafirmando a forte presença do modelo biomédico de cuidado na sociedade. Salvas algumas exceções, que envolveram o contato com enfermeiros, psicólogos e agentes comunitários de saúde, um senso comum em torno da memória clínica emergiu nas narrativas, convocando a autoridade médica para uma espécie de "prestação de contas" sobre o espaço dialógico como possibilidade interacional. A satisfação, tanto quanto a insatisfação, estiveram atreladas à presença do médico e à condução do processo pelo profissional. O ideário de um atendimento multiprofissional, que está em todos os níveis de atenção do SUS - desde a formação de equipes multiprofissionais na estratégia de Saúde da Família à oferta de atendimento especializado nas policlínicas em áreas para além da medicina, como fisioterapia e fonoaudiologia - não emerge nos depoimentos, em que outros atores que não sejam médicos não ganham destaque nas narrativas.

Adiante, foi importante observar a presença de discursos que deram destaque à perspectiva do acesso aos serviços do SUS como direito. Seja considerando-os positivos, a partir da universalidade da oferta, ou tomando-os apenas como uma obrigação governamental, os depoentes colocaram em cena este entendimento político presente e assegurado pela Constituição, ainda que sua materialização seja uma luta e uma conquista diárias. Não se observou, por exemplo, um conformismo com as experiências vivenciadas pelo fato de "serem de graça", o que diversas vezes constitui-se como regular no senso comum sobre o SUS. Do contrário, há nas narrativas uma expressão consciente sobre o uso do Sistema como direito civil, que apareceu em quatro dos 20 depoimentos.

Por fim, ainda que essa seja uma pequena amostra diante do universo de usuários do SUS, a pouca variedade dos tipos de serviços mencionados nos convida a uma reflexão a respeito da amplitude do SUS e seus desdobramentos. Dois universos de produção de sentidos foram demarcados: o das políticas de urgência e emergência, com suas UPAs e hospitais, e o das políticas de prevenção de doenças, especialmente com memória 
das campanhas e práticas de imunização. Falar sobre as experiências no SUS pareceu ser, ao fim e ao cabo, falar sobre a clínica como espaço de cuidado de interlocução. Muito pouco sobre uma clínica ampliada, que orienta, que dialoga, e muito sobre uma clínica que examina, que medicaliza, e que muitas vezes deixa a desejar na qualidade dessas práticas, do ponto de vista de seus narradores. Em seus depoimentos, revelou-se o ideário de que saúde se restringe ao acesso.

Conforme apresentamos na Introdução, quando se criou a campanha \#MinhaExperiênciaNoSUS, objetivou-se fomentar e estimular a circulação de experiências heterogêneas de uso e reflexão sobre o SUS; dar um passo a mais na direção de uma ruptura com o modelo unidirecional de troca de informações, que as redes sociais e suas linguagens por si só não são capazes de efetivar. Mapear os sentidos circulantes nos apontou que o acesso a esta heterogeneidade requer um esforço contínuo, mesmo persistente, que uma única campanha não é capaz de assegurar. Menos de três dezenas de depoimentos, em um universo de mais de 150 milhões de usuários do SUS e 78 milhões de perfis no Facebook, significa que a campanha caminhou muito aquém de sua potência, e é possível que isso tenha acontecido por variados motivos, que nos cabem analisar mais profundamente a partir de outros marcadores que não sejam as regularidades discursivas. Por exemplo, é possível analisar o perfil individual de cada um dos depoentes, traçando uma linha entre eles e seus contextos, a ponto de ser possível sugerir se de fato provocou-se uma circularidade diversificada ou promoveu-se uma continuidade de instrumentalização entre os que já têm espaços de fala assegurados pelos dispositivos de comunicação e/ou já estão sensibilizados pela defesa do direito à saúde e do SUS.

Para garantir que as novas tecnologias sejam instrumentos de mobilização e de fomento à participação social, é preciso possibilitar a autonomia e a sensibilização dos atores sociais que fazem dessas plataformas seus espaços de comunicação. No caso da campanha \#MinhaExperiênciaNoSUS, os responsáveis pela moderação dos depoimentos e comentários estavam abertos e teoricamente subsidiados para a acolhida da diversidade de depoimentos, possibilitando que todos fossem publicados, fossem negativos ou positivos, e fazendo esforço coletivo para responder a contento as questões propostas pelos depoentes. É sabido, contudo, que isso não reflete a totalidade de práticas institucionais no uso das TICs, quando os comentários e dúvidas são tantas vezes desconsiderados, excluídos, ou aguardam por tanto tempo uma resposta que perdem sua validade.

Estimular, via comunicação, o fortalecimento e a reflexão de um discurso público sobre funcionamento de políticas públicas como o SUS é tarefa complexa e repleta de armadilhas. Mesmo que as redes sociais como o Facebook e a comunicação em rede favoreçam maior e mais ágil interação com o público, os impasses, ruídos, apagamentos e tensões de todo o fazer comunicacional se refletem no espaço on-line. Entre as observações decorrentes deste processo, destacamos que falar de saúde pública, seja nas redes sociais on-line, seja em outros espaços midiáticos, em um contexto marcado por discursos 
adversos ao SUS e vivências e realidades de precarização da assistência e dos serviços de saúde oferecidos no país, é, por si, um primeiro grande desafio. Qualquer reflexão sobre o SUS implica o reconhecimento de seus limites, lacunas e equívocos. Mas, mesmo sob o risco de se abrir uma arena de demonização inclemente quanto a um sistema que, com suas falhas e gargalos, ainda carece de fortalecimento para se fazer de fato eficaz, o potencial de uma campanha como \#MinhaExperiêncianoSUS está na oportunidade de troca e diálogo com o público a partir das postagens e comentários. Essa potencialidade se constrói progressivamente, na observância dos sujeitos presentes nas páginas, no estabelecimento de um diálogo com eles, tornando-se fundamental para o levantamento de dados sobre a forma como o SUS é visto e debatido pela diversidade de usuários que frequenta as redes sociais.

Clarisse Castro Cavalcante e Daniela Muzi são doutorandas do Programa de Pós-Graduação em Informação e Comunicação em Saúde (PPGICS), do Instituto de Comunicação e Informação Científica e Tecnológica em Saúde da Fundação Oswaldo Cruz.

clarissecastrocavalcante@gmail.com

daniela.dmuzi@gmail.com

\section{Referências}

ARAÚJO, I. S; CARDOSO, J. M. Comunicação e Saúde. 20 ed. Rio de Janeiro: Editora Fiocruz, 2007. ARFUCH, L. O espaço biográfico: dilemas da subjetividade contemporânea. Tradução de Paloma Vidal. Rio de Janeiro: EdUERJ, 2010.

Brasil é maior usuário de redes sociais na América Latina. In: Forbes, São Paulo, 20 jun. 2016. Disponível em: http://www.forbes.com.br/fotos/2016/06/brasil-e-o-maior-usuario-de-redes-sociaisda-america-latina/ Acesso em: 22 mai. 2017.

CASTELLS, M; CARDOSO, G. A sociedade em Rede: do conhecimento à acção política. Lisboa: Imprensa Nacional, 2005.

CAVALCANTE, C. C. Os sentidos do Sistema Único de Saúde na mídia impressa do Ceará - Um estudo do jornal O Diário do Nordeste [dissertação]. Rio de Janeiro: Instituto de Comunicação e Informação Científica e Tecnológica em Saúde, Fundação Oswaldo Cruz; 2014.

CHARAUDEAU, P. Discurso das mídias. São Paulo: Contexto, 2006.

FOUCAULT, M. A Arqueologia do Saber. Rio de Janeiro: Forense Universitária, 2015.

GOFFMAN, E. Interaction Ritual: Essays on Face-To-Face Behavior. New York: Pantheon Books, 1967.

KIRKWOOD, K. "If They Build It, They Will Come": Creating Opportunities for E-learning Communities 
of Practice. Language and Learning Skills Unit. In: Universitas 21 Conference on E-learning and Pedagogy, 2006, Guadalajara. Actas...

LEMOS, A. Cibercultura: Alguns pontos para compreender nossa época. In: Lemos A; Cunha P. Olhares sobre a Cibercultura. Porto Alegre: Sulina. p.11-23. 2003.

MAFRA, R L M. Mobilização social e comunicação: por uma perspectiva relacional. Mediação, Belo Horizonte, v. 11, n. 10, jan./jun. de 2010.

NUNES, G. M et al. Os Desafios da Participação Popular no Sistema Único de Saúde. In: III Encontro Nacional de Pesquisadores em Gestão Social, 2009, Juazeiro/BA - Petrolina/PE. Anais...

OLIVEIRA J. Facebook: a apresentação de si entre o privado e o público. Mediação, Belo Horizonte, v. 19, n. 25, jul./dez. de 2017.

PÊCHEUX, M. Discurso: Estrutura ou acontecimento. 5 ed. ORLANDI, E. P. (trad). Campinas: Ed. Pontes, 2008.

Semântica e Discurso - uma crítica à afirmação do óbvio. Campinas: Editora da Unicamp, 1995.

RECUERO, R. Curtir, compartilhar, comentar: trabalho de face, conversação e redes sociais no Facebook. In: Verso e Reverso, v. 28, n. 68, 2014.

SILVA, G. M. A crítica ao SUS no jornal Folha de São Paulo [dissertação]. Uberlândia: Instituto de Psicologia, Universidade Federal de Uberlândia; 2010. 